\title{
Experimental study of properties of heavy concrete with bottom ash from power stations
}

\author{
Victor Bondar ${ }^{1}$, Volodymyr Shulgin ${ }^{1}$, Oksana Demchenko ${ }^{1}$, and Ludmila Bondar $^{1 *}$ \\ ${ }^{1}$ Poltava National Technical Yuri Kondratyuk University, Department of technology building designs, \\ products and materials, Pershotravnevyi Avenue, 24, Poltava, 36011, Ukraine
}

\begin{abstract}
This article deals with the influence of cement quantity, plasticizing additives and compaction time on the strength and water consumption of concrete during its manufacturing using bottom ash from a thermal power station. The study was carried out using three factorial experiments. Variables varied on three levels. The obtained pattern functions characterize a relationship between strength, water consumption and variable factors. These factors include cement quantity, plasticize additives and compaction time. Compilation of Pareto effect charts allowed estimation of the significance of function indexes. Analysis of surface pattern function has revealed the optimal correlation between additive quantity and compaction time, cement quantity and additive quantity, cement quantity and compaction time. Compression strength of concrete was taken as the pattern in the pattern function. When analyzing the pattern function with water consumption as a pattern, optimal correlations between additive quantity and compaction time, cement quantity and additive quantity, cement quantity and compaction time were revealed. Application of STATISTICA 12 software has specified values of factors when the maximum strength is achieved. Correlations of components which have an impact on water consumption have been determined. The conclusions contain the quantitative findings of the study.
\end{abstract}

\section{Introduction}

Significant amount of bottom ash is produced during coal burning for generation of thermal and electrical energy at thermal power stations. One of the ways of safe disposal of this waste is its use in the building industry for heavy concrete manufacturing.

An optimal quantity of bottom ash in a heavy concrete mixture is calculated by compiling the concrete composition provided that all necessary indicators of its quality are reached [1]. Concrete mixtures with bottom ash possess a higher viscosity, better mobility, lower water separation, and segregation. It makes bottom ash based mixtures perfect for use in monolith concreting. Slag use decreases a necessary quantity of cement, and therefore, decreases the exothermy of concrete. That allows prolonging the time before the solidification start and, therefore, prolongs the period of time when the concrete is available for use [2-6]. The

\footnotetext{
* Corresponding author: 1vbondar06@gmail.com
} 
features of this kind of concrete are not investigated enough. As well as the influence of bottom ash on mechanical properties of concrete [7].

\section{Research results}

\subsection{Materials for concretes with use of ash and slag}

This research aim is to determine the effect of concrete composition, which includes bottom ash, on its physical and mechanical properties. Another task is to compile an optimal composition of concrete with strength class C25/20, using ash and slag as additives.

For the research, we used a concrete mixture of the following composition. Cement CEM I $42.5 \mathrm{~N}$ is characterized by high early strength, high content of $C_{3} S$, and low content of $C_{3} A$ [8].

Ash and slag (bottom slag) from Starobeshivska thermal power station the true density of which is $2.6 \mathrm{~g} / \mathrm{cm}^{3}$; bulk density is $1.206 \mathrm{~g} / \mathrm{cm}^{3}$; coarseness factor is 1 ; water requirement is $24 \%$. Granite gravel was used as coarse-grained filler, its fraction was 5 to $10 \mathrm{~mm}$, void ratio is $47 \%$, bulk density is $\rho_{b}=1350 \mathrm{~kg} / \mathrm{m}^{3}$, true density is $\rho_{t}=2.71 \mathrm{~g} / \mathrm{cm}^{3}$. Polycarboxylate superplasticizer GLENIUM 51 served as the additive.

\subsection{Mathematical experiment planning}

The research planning based on the 3-factorial experiment on 3 levels. Cement quantity, concrete mixture compaction time, and quantity of plasticizer additive were the variable factors. In order to ensure a proper porosity at each level, water-cement $(V / C)$ ratio was 0.45 . It also accounted for peculiarities of initial materials structure. If $V / C$ is lower than 0.45 , it will be impossible to provide a proper compaction index foe the mixture. There were control specimens manufactured for the research. Quartz sand used for manufacturing the specimens, and its strength was $31 \mathrm{~N} / \mathrm{mm}^{2}$.

\subsection{Regression analysis of concrete strength research}

According to concrete strength research results, pattern function was obtained (1) using STATISTICA 12 software

$$
\begin{aligned}
Y_{R}= & 30.07+0.525 x_{1}+0.78 x_{2}-2.3 x_{3}-0.34 x_{1}^{2}+0.44 x_{2}^{2}+ \\
& +0.24 x_{3}^{2}-1.18 x_{1} x_{2}-0.75 b_{13} x_{1} x_{3}-0.57 x_{2} x_{3}
\end{aligned}
$$

The obtained model is adequate according to lack-of-fit test. Pattern function surfaces is plotted in accordance with equation (1), it showed in figures 2-4. Pareto effect chart shows (fig. 1) that the equation indexes at $x^{3}$ are the most significant in the model. This means that pattern function even in a stationary area has got some curvature and can be described by a polynomial function of the second degree. The results allow estimation the adequateness of the model since there were three parallel experiments conducted at level 0 .

Analysis of surface shape shown in Figure 2 reveals that the maximum strength was obtained when compaction time was 3 minutes and additive quantity was 8 liters. Further increasing the additive quantity could not lead to any increase in concrete strength.

Analysis of surface shape in figure 3 shows that the maximum strength is reached at 390 $\mathrm{kg}$ of cement and 81 of the additive. 


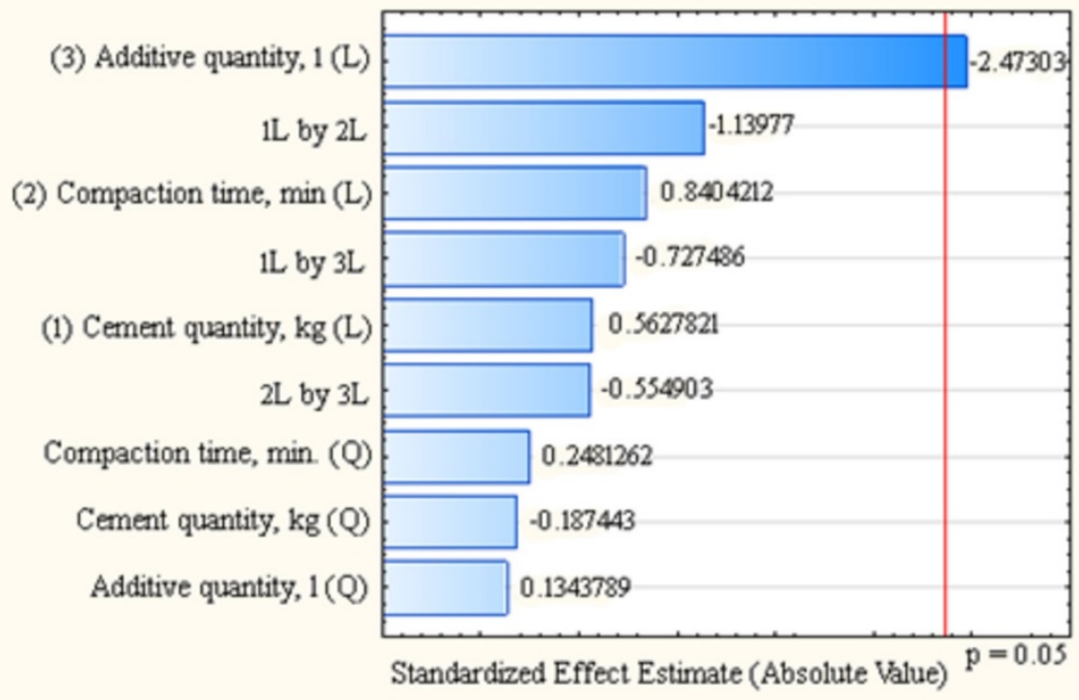

Fig. 1. Pareto effect chart for estimation the statistical significance of the regression equation indexes of concrete strength.

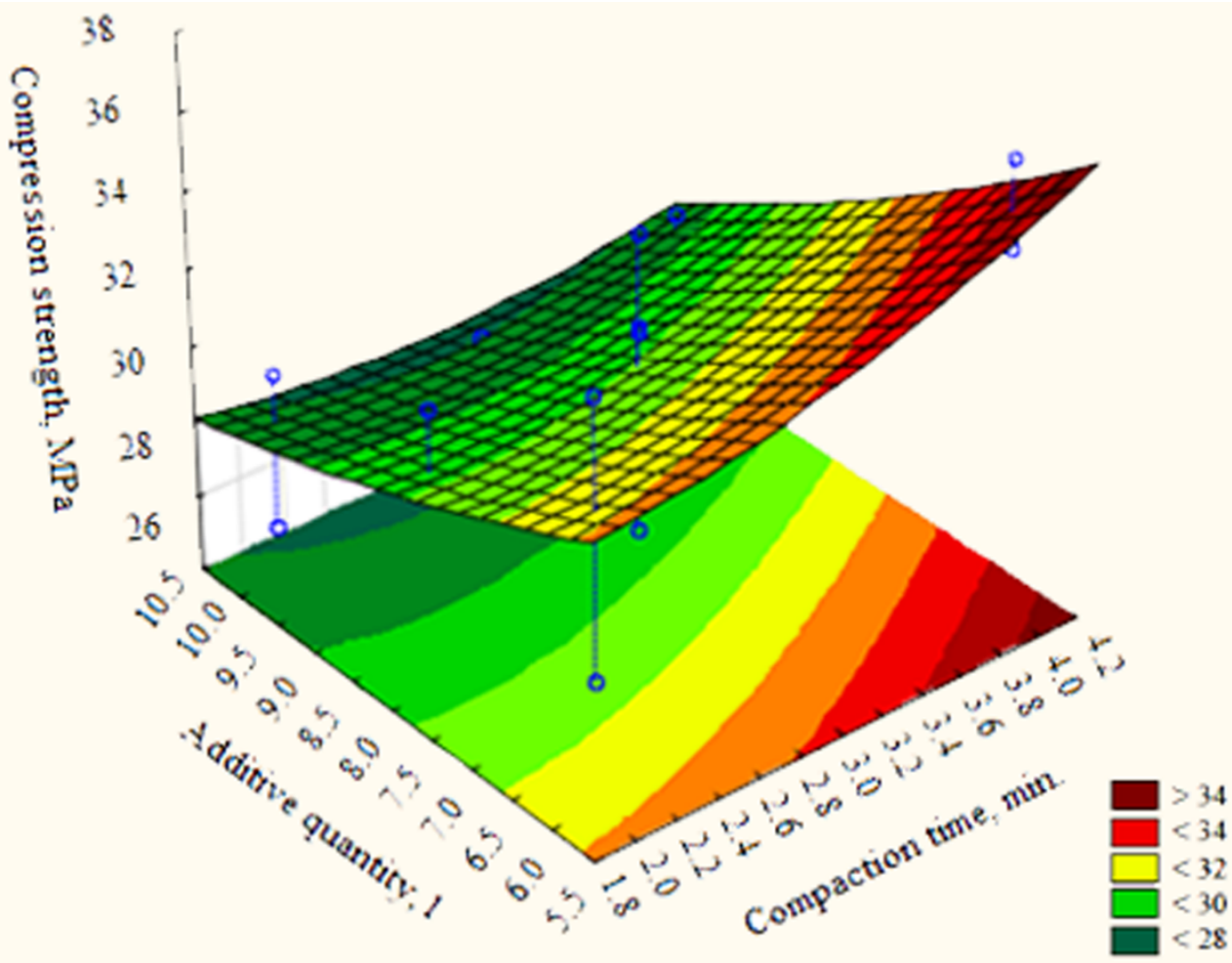

Fig. 2. Overall view of pattern function surface for limit compression strength of concrete dependent on additive quantity and compaction time of concrete mixture. 


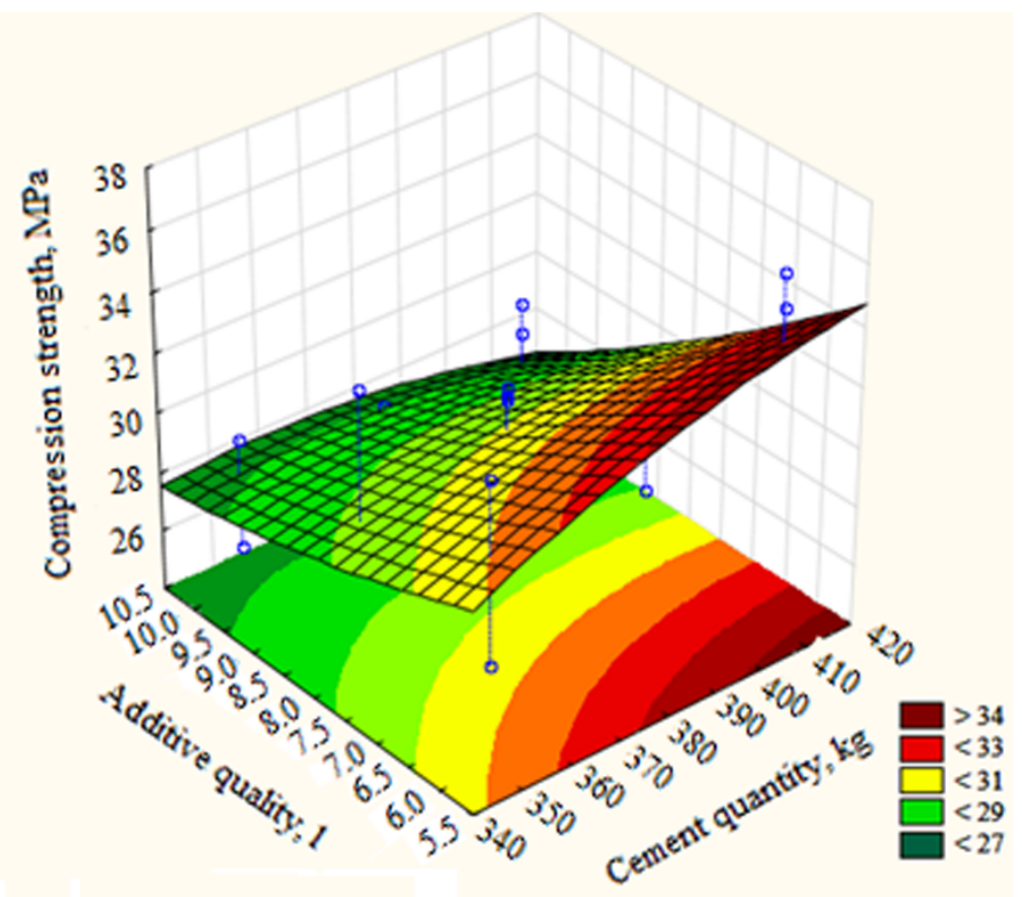

Fig. 3. Overall view of pattern function surface for limit compression strength of concrete dependent on additive quantity and cement quantity.

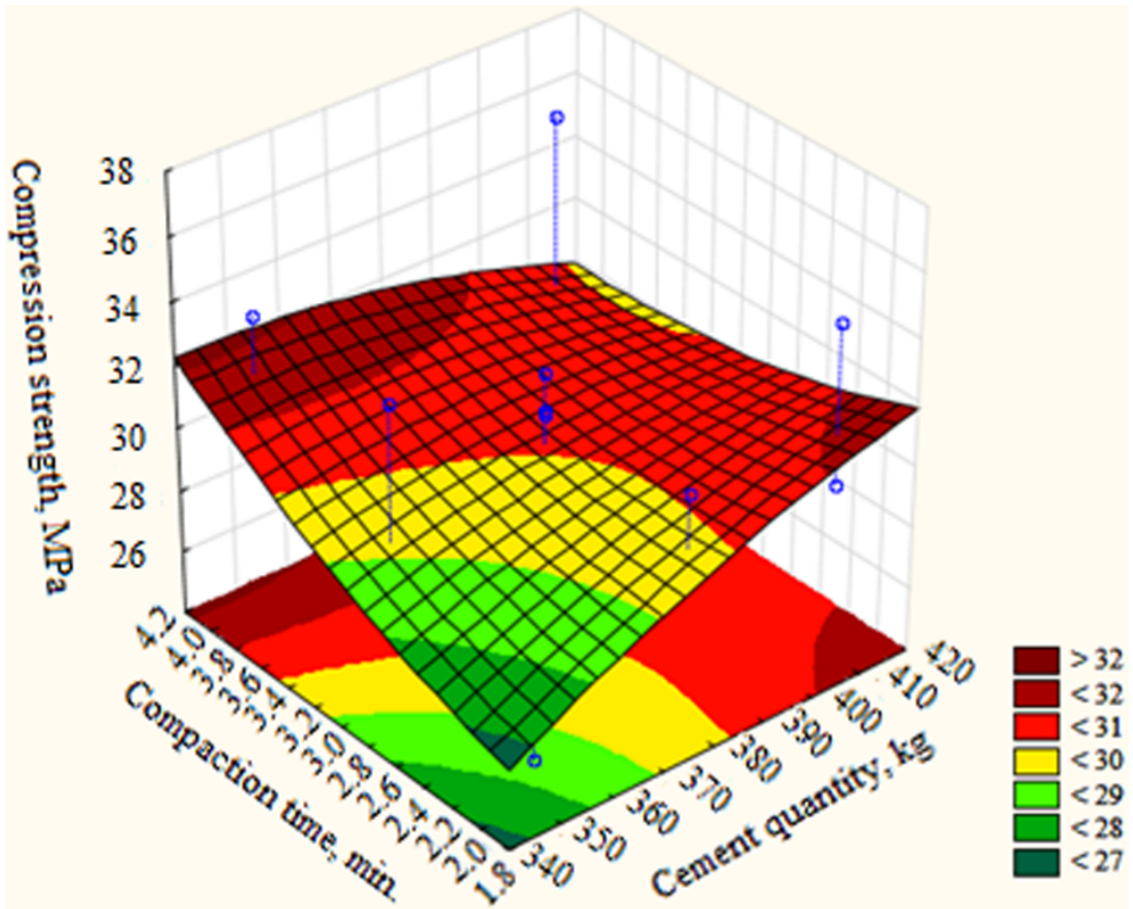

Fig. 4. Overall view of pattern function surface for limit compression strength of concrete dependent on cement quantity and compaction time of concrete mixture. 
Analysis of surface shape in Figure 4 shows that the maximum strength is reached at 3 min. of compaction time and $400 \mathrm{~kg}$ of cement. Further increasing of the quantity of additive doesn't lead to any increasing in concrete strength.

Visual analysis of the surfaces reveals only approximate values of optimal relations of components. However, STATISTICA software allows determination of the factors at which the investigated value reaches its maximum magnitude (Table 1).

Table 1. Critical values of variables.

\begin{tabular}{|c|c|c|c|}
\hline Factor & Observed minimum & Critical values & Observed maximum \\
\hline Cement quantity, $\mathrm{kg}$ & 350.000 & 350.056 & 410.000 \\
\hline Additive quantity, 1 & 6.000 & 12.990 & 10.000 \\
\hline Compaction time, min. & 2.000 & 2.410 & 4.000 \\
\hline
\end{tabular}

\subsection{Regression analysis of concrete water consumption}

According to concrete water consumption research results, pattern function has been obtained (2)

$$
\begin{aligned}
Y w=2.23 & +0.06 x_{1}+0.4 x_{2}-1.4 x_{3}-1.54 x_{1}^{2}+0.23 x_{2}^{2}+ \\
& +0.95 x_{3}^{2}-0.18 x_{1} x_{2}-1.16 b_{13} x_{1} x_{3}-0.63 x_{2} x_{3}
\end{aligned}
$$

Pareto effect chart shows (fig. 5) that the equation indexes of combined cement and additive quantities are the most significant in the model.

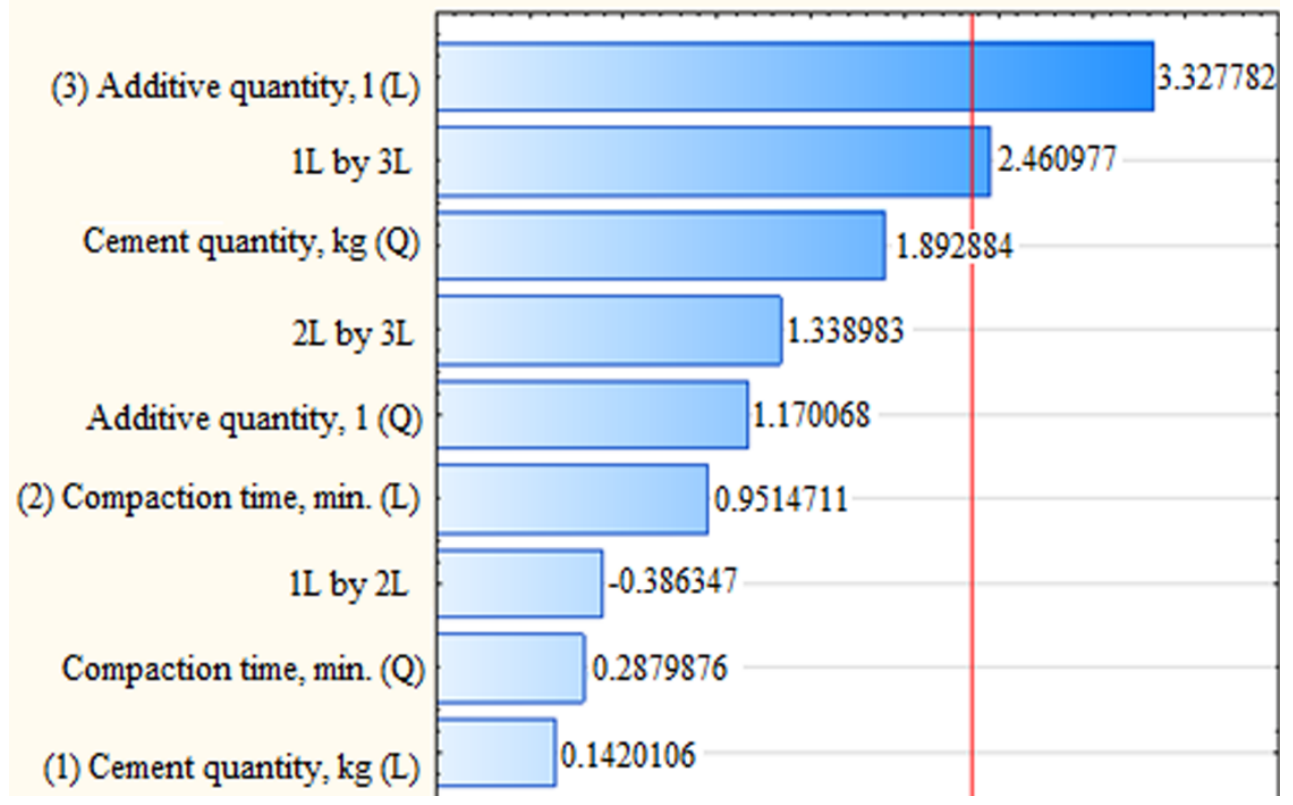

Fig. 5. Pareto effect chart for estimation the statistical significance of the regression equation indexes of concrete water consumption. 


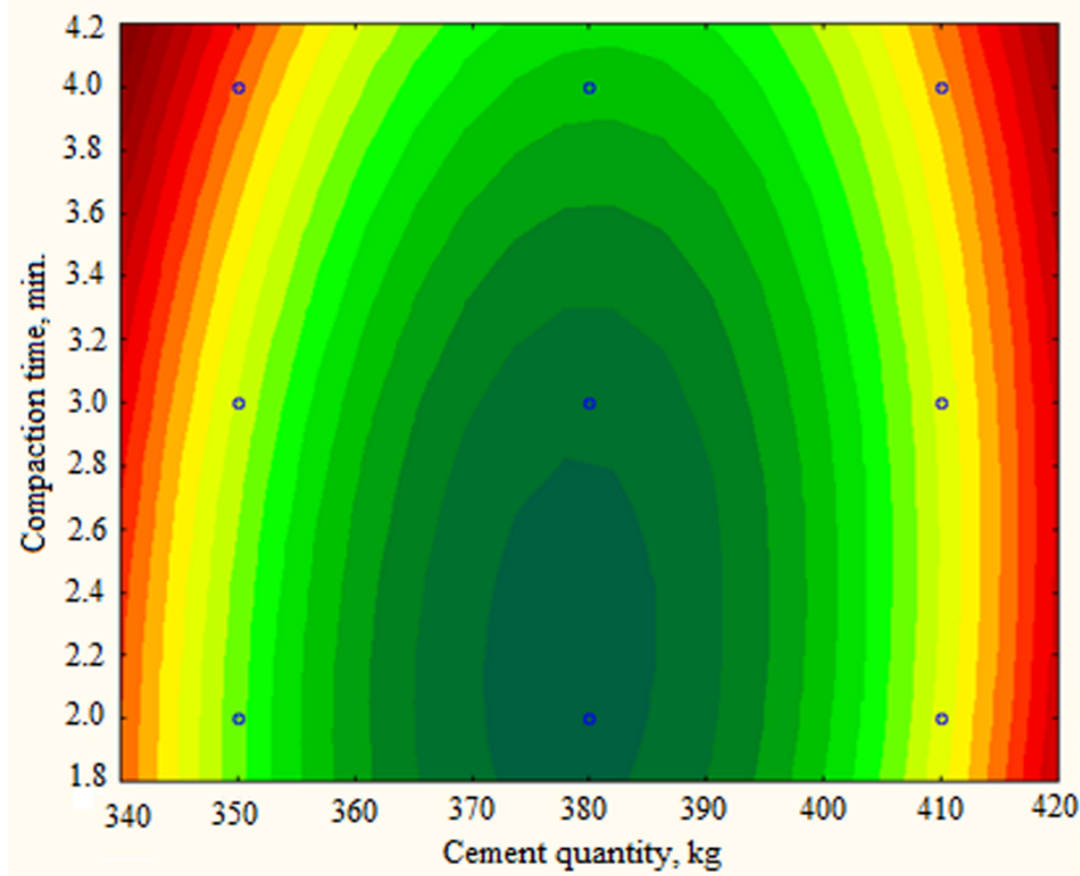

Fig. 6. Isolines of pattern function surface of water consumption against quantities of cement and additives.

Analysis of isolines of pattern function surface shows that the minimum water consumption could be reached at cement quantity about $390-400 \mathrm{~kg}$, and 8 liters of additive.

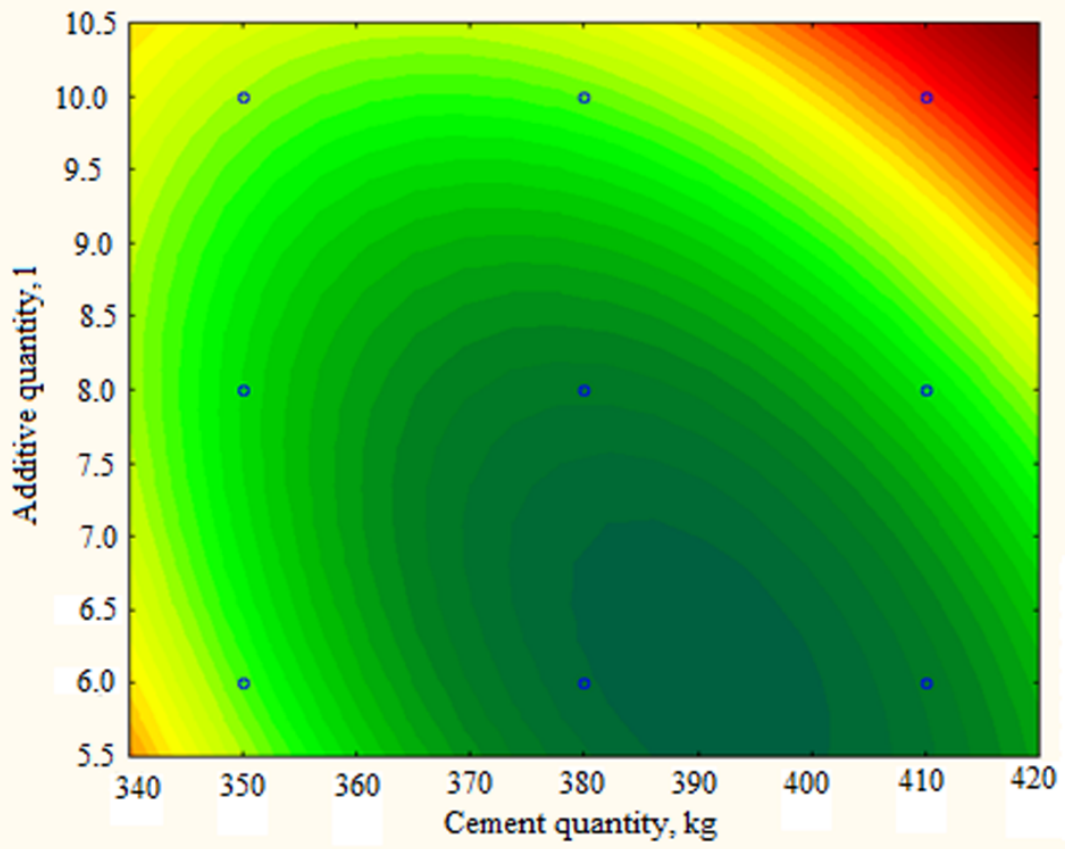

Fig. 7. Isolines of pattern function surface of water consumption against quantity of cement and compaction time. 
Analysis of isolines of pattern function surface shows that the minimum water consumption could be reached at cement quantity about $390 \mathrm{~kg}$, and 3 minutes of compaction time.

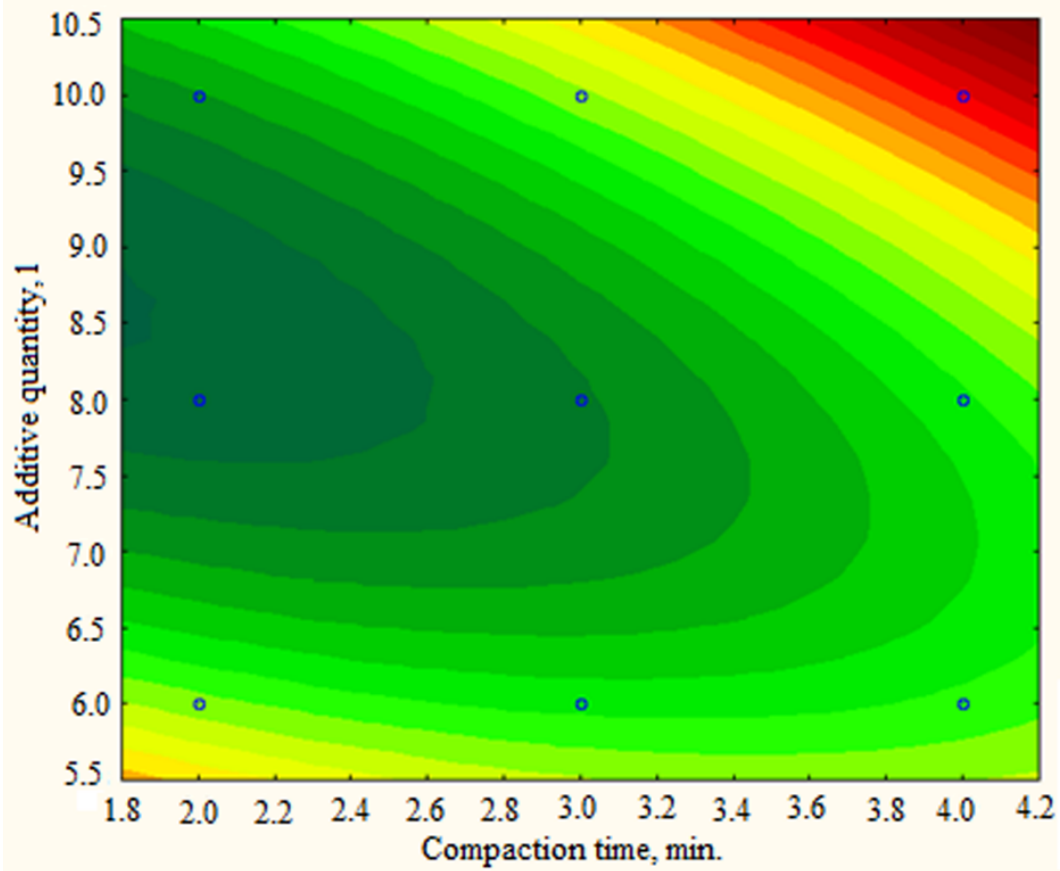

Fig. 8. Isolines of pattern function surface of water consumption against quantity of additive and compaction time.

Analysis of isolines of pattern function surface shows that the minimum water consumption could be reached at additive quantity about 7.5 to 8.1 and 3 to 3.6 minutes of compaction time.

The values of obtained relations of components during the study of its influence on water consumption is shown in table 2 .

Table 2. Critical values of variables.

\begin{tabular}{|c|c|c|c|}
\hline Factor & Observed minimum & Critical values & Observed maximum \\
\hline Cement quantity, kg & 350.000 & 379.100 & 410.000 \\
\hline Additive quantity, 1 & 6.000 & 7.750 & 10.000 \\
\hline Compaction time, min. & 2.000 & 1.800 & 4.000 \\
\hline
\end{tabular}

\section{Conclusion}

Bottom ash usage as a fine filler allowed us to obtain concrete of $36 \mathrm{~N} / \mathrm{mm}^{2}$ strength. The strength of concrete with quartz sand was $31 \mathrm{~N} / \mathrm{mm}^{2}$. Therefore, bottom ash with additive provides $14 \%$ higher strength of concrete and could be used instead of sand in concrete mixtures.

Improvement of cement quantity causes increase of compaction index. It was determined that optimal compaction time for concrete is 3 minutes. The minimum value of water consumption is $2.0 \%$. This value was reached when the quantities of cement and plasticizer additive are $390 \mathrm{~kg}$ and 8.1 respectfully.

Water consumption of control specimens with sand filler is $0.6 \%$ higher than that of concrete with bottom ash. 


\section{References}

1. P.V. Krivenko, E.K. Pushkareva, V.I. Gotz, G. Y. Kovalchuk, Tsementy i betony na osnovi palyvnykh zol ta shlakiv, Kiev (2012)

2. Nurul Izzati Raihan Ramzi Hannan, Shahiron Shahidan, Noorwirdawati Ali, Mohamad Zulkhairi Maarof, MATEC WEB CONF, 97 (2017)

3. V.M. Malhotra, P.K. Mehta, High-Performance, High-Volume Fly Ash Concrete, Inc., Canada (2002)

4. Seyoon Yoon, P.J.M. Monteiro, D.E. Macphee, F.P. Glasser, Mohammed Salah-Eldin Imbabi, CONSTR BUILD MATER, 54, 432-442 (2014)

5. V.M. Malhotra, High-Performance, Concrete International 24(7), 30-34 (2002)

6. P.K. Mehta, International Workshop on Sustainable Development and Concrete Technology, 3-14 (2004)

7. N. Zaichenko, A. Serduk, Visnyk DNABiA, 1(99), 137-144 (2013)

8. M. Thomas Concrete Thinking, Portland Cement Associations, 1-24 (2007) 